\title{
Os adjetivos participiais no português
}

\author{
Maria José Foltran \\ Gisele Crisóstimo* \\ Universidade Federal do Paraná
}

\section{Abstract}

In this paper we analyse the occurrences of verbal participial forms as adjuncts within a noun phrase. We also establish constraints that do not allow certain monoargumental verbs to occur in this environment. Differently from participles of two argument verbs, we noticed that some participles of one argument verbs cannot work as adjectives, while others can. This is because of the type of arguments each verb selects: since the arguments of certain one argument verbs share the same features of internal arguments, the participles of these verbs can occur as adjectives, and therefore we can classify these as unaccusative verbs. We also investigate the semantic properties of the arguments which allow a participial form as a modifier. 


\section{INTRODUÇÃO}

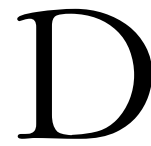

e modo geral, quando se procura estabelecer as propriedades dos verbos inacusativos, chega-se ao uso do particípio como uma forma de diagnosticar se determinado verbo pertence ou não a essa classe. Este trabalho inverte essa perspectiva e parte da observação do uso da forma participial, mais especificamente dentro do sintagma nominal e na função de predicativo, buscando detalhar melhor a distribuição e comportamento dos particípios. Percorrendo esse caminho, chega-se inevitavelmente à classe dos inacusativos, mas com uma visão melhor das outras classes de verbos.

Fazemos, primeiramente, um estudo comparativo entre as ocorrências dos adjetivos participiais, derivados de verbos que pertencem a subcategorias distintas: os biargumentais e os monoargumentais. Trabalhamos, nesta pesquisa, com construções vigentes no português do Brasil.

Demonstramos, através de testes, que o particípio dentro de um sintagma nominal e na posição predicativa possui todas as características comuns aos adjetivos. A partir daí, evidenciamos a irregularidade, nesses ambientes, no uso dessas formas participiais originárias dos verbos monoargumentais.

Em seguida, fazendo uso da Teoria Generalizada dos Papéis Temáticos, procuramos determinar as propriedades semânticas que licitam o uso do particípio como modificador do nome ou como predicativo e as que restringem esse uso. 


\section{O VERBO E SEUS ARGUMENTOS}

Entende-se por argumento os constituintes que são selecionados pelos verbos, ou seja, constituintes cuja presença se torna obrigatória para que a sentença seja gramatical. Tomemos, por exemplo, a sentença em (1).

\section{(1) Meu pai comprou um carro ontem.}

Para que uma sentença com o verbo comprar seja gramatical, i. e., uma sentença aceitável por falantes da língua, é necessária a presença de dois argumentos: quem comprou e o que foi comprado. Já o constituinte ontem não é selecionado pelo verbo, constituindo, assim, o que chamamos de adjunto.

Os verbos são, desse modo, classificados quanto ao número de argumentos que selecionam. Os transitivos selecionam dois ou três argumentos e os intransitivos, apenas um argumento. As sentenças das línguas naturais se estruturam sempre em sujeito e predicado. Sendo assim, um dos argumentos do verbo deve ocupar a posição sintática de sujeito. ${ }^{1}$ Se o verbo seleciona apenas um argumento, esse argumento terá que, obrigatoriamente, ocupar tal posição. ${ }^{2}$

A sentença em (1) contém um verbo transitivo, com dois argumentos: meu pai e um carro. Dizemos que esses argumentos saturam as posições abertas pelo verbo (posição de sujeito e de complemento). Vamos, aqui, chamar esses verbos de biargumentais.

Já os tradicionalmente chamados de intransitivos, por sua vez, selecionam somente um argumento que, pelo motivo que expusemos, preenche a posição sintática de sujeito. Observemos a sentença em (2).

(2) O sol brilha.

Brilhar é um verbo que precisa de apenas um argumento: aquilo que brilha. Esse argumento ocupa a posição de sujeito e qualquer outro constituinte que for inserido será um adjunto. Em (3), por exemplo, o constituinte todos os dias é um adjunto e não um argumento. 
(3) O sol brilha todos os dias.

Devido à presença obrigatória de apenas um argumento, vamos chamar esses verbos, aqui, de monoargumentais.

Tendo isso em vista, vamos apresentar o que observamos em relação à ocorrência dos adjetivos participiais originados de verbos biargumentais e monoargumentais.

\section{OS ADJETIVOS PARTICIPIAIS COM VERBOS BIARGUMENTAIS}

É sabido que os particípios podem ocorrer de diferentes formas: a) na formação de tempos compostos, como exemplifica (4a); b) na formação de passiva, como em (4b); c) na posição de predicativo, como mostra (4c); d) na posição de adjunto adnominal, como um adjetivo, em (4d). ${ }^{3}$

(4) a. Ele tem comprado muitos livros.

b. Os livros foram comprados nessa loja.

c. Os alunos estão preocupados com a prova.

d. Os alunos preocupados estudam mais.

Este trabalho se volta preferencialmente para as ocorrências do particípio como adjunto adnominal, do tipo que aparece em (4)d. Ou seja, o particípio, aí, está inserido no sintagma nominal que ocupa a posição de sujeito da sentença. A preocupação central foi examinar a possibilidade de o particípio se inserir no sintagma nominal como adjunto, independentemente da posição sintática que esse sintagma nominal ocupa. Por apresentar um comportamento bastante semelhante, consideramos, em alguns momentos, as ocorrências como predicativo, do tipo apresentado em (4)c.

O argumento interno dos verbos biargumentais, isto é, aquele que não ocupa a posição de sujeito, pode ser direto (sem preposição), ou indireto (com preposição). Vamos, a princípio, levar em consideração apenas os que têm objeto direto. Observando o comportamento dos particípios que derivam de verbos biargumentais, 
verifica-se que o objeto direto não oferece nenhuma resistência em atuar como adjetivo. Podemos afirmar que todos os particípios originados de verbos biargumentais podem ocorrer como adjetivos dentro de um sintagma nominal.

(5) a. A televisão transmitiu as notícias via satélite.

b. As notícias transmitidas via satélite chocaram a população.

(6) a. João comprou um livro novo.

b. O livro comprado desapareceu.

(7) a. Maria devolveu o envelope.

b. O envelope devolvido estava rasgado.

O fato de o particípio desses verbos biargumentais poder ocorrer como adjetivo adjunto está correlacionado com o fato de serem as estruturas com verbos biargumentais com objeto direto as únicas a se submeterem à formação de passivas. Em outras palavras, uma estrutura passiva só se forma a partir de uma sentença com um argumento interno. Isso sinaliza alguns fatos que vamos retomar no decorrer deste trabalho.

\subsection{Os adjetivos participiais com verbos monoargumentais}

A ocorrência dos adjetivos participiais com verbos monoargumentais não apresenta a regularidade que se pode observar nos verbos biargumentais: alguns particípios gerados a partir de verbos monoargumentais podem ocorrer como adjetivos dentro do sintagma nominal, enquanto outros não. Apresentamos, a seguir, alguns exemplos. Em (8), temos construções com verbos monoargumentais que são possíveis no português brasileiro. Já os exemplos em (9) mostram particípios de verbos monoargumentais que não podem ser usados como adjetivos.

Observamos que a maioria dos particípios que pode ocorrer como adjunto do nome dentro do sintagma nominal também pode ocorrer na posição de predicativo. Os verbos de movimento e direção são os que oferecem alguma restrição e esse fato será retomado mais adiante. 
(8)

\begin{tabular}{|l|l|}
\hline a. As folhas caem no outono. & $\begin{array}{l}\text { As folhas caídas das árvores adubam } \\
\text { a terra. }\end{array}$ \\
\hline b. Os resultados saíram ontem. & $\begin{array}{l}\text { ?Os resultados saídos ontem não } \\
\text { agradaram os concorrentes. }\end{array}$ \\
\hline c. A professora cansou. & $\begin{array}{l}\text { A professora cansada dispensou os } \\
\text { alunos. }\end{array}$ \\
\hline $\begin{array}{l}\text { d. A informação chegou tarde. } \\
\text { ?A informação chegada no final da } \\
\text { reunião animou o pessoal. }\end{array}$ \\
\hline $\begin{array}{l}\text { e. Filho dos outros cresce } \\
\text { rapidamente. }\end{array}$ & Filhos crescidos dão mais trabalho. \\
\hline $\begin{array}{l}\text { f. A semente germinou. } \\
\text { A semente germinada havia passado } \\
\text { por diferentes processos. }\end{array}$ \\
\hline
\end{tabular}

(9) a. O aluno bocejou na aula. $\quad$ *O aluno bocejado saiu da sala.

\begin{tabular}{|l|l|}
\hline b. A menina soluçou. & $\begin{array}{l}\text { *A menina soluçada despertou } \\
\text { compaixão. }\end{array}$ \\
\hline c. Os atletas correram no parque. & $\begin{array}{l}\text { *Os atletas corridos ambicionavam o } \\
\text { prêmio. }\end{array}$ \\
\hline d. Os cães ladraram a noite toda. & $\begin{array}{l}\text { *Os cães ladrados assustaram os } \\
\text { visitantes. }\end{array}$ \\
\hline e. O chefe telefonou cedo. & *O chefe telefonado convocou a reunião. \\
\hline f. O conferencista falou bem. & *O conferencista falado foi aplaudido. \\
\hline
\end{tabular}

(10) a. As folhas estão caídas.

b. *Os resultados estão saídos. *Os resultados são saídos.

c. A professora está cansada.

d. *A informação está chegada. ?A informação é chegada.

e. Os filhos estão crescidos.

f. A semente está germinada.

Já os que não podem ocorrer como adjunto também não atuam como predicativos.

(11) a. *O aluno está bocejado.

b. *A menina está soluçada. 

c. *Os atletas estão corridos.
d. *Os cães estão ladrados.
e. *O chefe está telefonado.
f. *O conferencista está falado.

Esses dados nos levam à conclusão de que os verbos monoargumentais se dividem em duas classes. A partir da forma como os dados se distribuem, as perguntas que nortearam o desenvolvimento da pesquisa foram:

- Os particípios se comportam como verdadeiros adjetivos no ambiente sintático de adjunto e de predicativo?

- Como caracterizar as duas classes formadas pelos verbos monoargumentais?

- Por que o argumento de alguns desses verbos pode ser modificado pelos adjetivos participiais, enquanto o de outros não?

A análise dessas e de outras questões é encaminhada nas seções seguintes.

\section{OS PARTICÍPIOS COMO ADJETIVOS}

Segundo Pimenta-Bueno (1986), os particípios não se comportam como um grupo lexicalmente uniforme. Às vezes, comportam-se como verbos, como quando ocorrem nos tempos compostos; e, às vezes, comportam-se como formas nominais. A possibilidade de ocorrer na posição de predicativo e na de adjunto já indica o caráter nominal do particípio, pois esses são ambientes próprios dos adjetivos e, nesses ambientes, o particípio se submete à flexão própria dos nomes, ou seja, à flexão de gênero e número. ${ }^{4}$ Em (12) e (13), apresentamos a possibilidade de o particípio ser substituído por um "verdadeiro" adjetivo e mostramos a obrigatoriedade da flexão em gênero e número.

(12) a. A professora estava cansada.

b. A professora estava disposta. 

c. As professoras estavam cansadas.
d. Os alunos estavam cansados.

(13) a. A perna do gato está inchada.

b. A perna do gato está suja.

d. O joelho do gato está inchado.

e. Os dedos estão inchados.

Um ambiente também típico dos adjetivos é o ambiente de adjunto do nome dentro do sintagma nominal. Nesse contexto, os particípios compartilham das mesmas propriedades dos adjetivos: flexionam-se em gênero e número e podem ocorrer na posição pré ou pós-nominal.

(14) a. A professora cansada dispensou a classe.

b. A cansada professora dispensou a classe.

c. Os alunos cansados tiveram baixo aproveitamento.

(15) a. O ônibus desaparecido cruzou a fronteira.

b. O desaparecido candidato entrou inesperadamente na reunião.

c. As cartas desaparecidas levantaram suspeita.

Seguindo a reflexão de Pimenta-Bueno, vamos testar como os particípios se comportam, tendo em vista propriedades que são próprias dos adjetivos.

Os particípios, como os adjetivos, podem ocorrer em expressões comparativas tais como tão .... quanto, mais.... (do)que e menos..... (do) que, como pode ser observado em (16).

(16) a. A perna está tão inchada quanto o joelho.

b. As folhas estão mais caídas do que as flores.

c. João está menos cansado do que Paulo.

d. Uma pessoa menos cansada poderia levar o material para cima.

Alguns particípios não respondem positivamente a esse teste pelo fato de não poderem ser graduados: algo que desapareceu, por 
exemplo, não pode estar mais ou menos desaparecido. Isso explica a estranheza de (17).

(17) *O ônibus está mais desaparecido do que o caminhão.

Nessa linha, os particípios, tal como os adjetivos, podem aparecer numa estrutura superlativa relativa, como $o(s)$ mais... ou $o(s)$ menos.

(18) a. Os garotos são os mais crescidos do grupo.

b. As meninas são as menos cansadas da turma.

Os particípios, também como os adjetivos, têm formas superlativas absolutas sintéticas, como exemplificado em (19).

(19) a. Essa família é evoluidissima.

b. A perna está inchadíssima.

c. Um professor irritadíssimo com a turma não é a pessoa mais indicada para isso.

Os modificadores de grau como muito, bem e bastante modificam adjetivos. Os particípios podem ocorrer modificados por eles.

(20) a. Ele estava muito adoecido.

b. Encontrei as crianças bastante crescidas.

d. Achei a discussão bem evoluída.

e. Um trabalho bem desenvolvido é o ideal para participar do concurso.

Outra propriedade que comprova a familiaridade dos particípios com os adjetivos é a de poderem ocorrer coordenados. Sabemos que elementos coordenados devem estar no mesmo paradigma. Em (21)a, confusa é um adjetivo que está apropriadamente coordenado ao particípio decaída. Já em (21)b, o particípio está coordenado a dois verbos e a sentença é agramatical. Isso prova que o particípio, nesse contexto, pertence ao paradigma dos nomes.

(21) a. Como essa empresa está confusa e decaída!

b. *Como essas crianças correm, gritam e crescidas! 
O comportamento do particípio nesses testes nos permite afirmar que ele, quando em posição de predicativo ou de adjunto, possui todas as propriedades apresentadas pelos adjetivos. Portanto, nesses ambientes, os particípios funcionam como adjetivos e não como verbos.

A questão que se coloca agora é: por que os particípios de alguns verbos monoargumentais não podem ser usados como adjetivos? O que se pode asseverar é que não é a forma particípio que impede esse uso, já que os particípios, como vimos, atuam como elementos nominais do tipo dos adjetivos. Também não é o fato de o verbo ter um único argumento, pois alguns deles, conforme mostramos na seção 2.1, geram particípios que podem aparecer nos ambientes próprios de adjetivos. Portanto, a explicação deve estar na natureza do verbo que gera o particípio. Essa é a questão a ser explorada na próxima seção.

\section{ANÁLISE DAS RESTRIÇÕES QUE ATUAM SOBRE OS ADJETIVOS PARTICIPIAIS DOS VERBOS MONOARGUMENTAIS}

Vimos, nas seções anteriores, que o particípio equivale a um adjetivo, quando na posição sintática de predicativo ou de adjunto do nome. Vimos também que, quando o particípio é formado a partir de um verbo biargumental, o seu emprego como adjetivo nas posições mencionadas não sofre restrições. No entanto, quando o particípio decorre de um verbo monoargumental, o seu uso como adjetivo é restringido: alguns particípios podem ser usados no contexto em questão, enquanto outros não. Nossa tarefa, agora, é levantar hipóteses para uma análise que explique tais restrições.

Os particípios gerados pelos verbos biargumentais podem ser usados como adjetivos adjuntos dentro do sintagma nominal desde que o nome a ser modificado seja o complemento interno (objeto direto) do verbo. Assim, de uma sentença como (22a) pode ser criada uma sentença como (22b), mas não uma sentença como (22c). 
(22) a. O aluno comprou o livro que o professor sugeriu.

b. O livro comprado ...

c. *O aluno comprado ....

Portanto, o nome a ser modificado pelo particípio adjetivo precisa ser um termo que não veicule a interpretação de "agente", 5 ou um argumento que não manifeste controle sobre a ação denotada pelo verbo. Nesse sentido, é compreensível que, nas estruturas de dois argumentos, seja o argumento externo que, de modo geral, veicule esse tipo de interpretação. A questão crucial colocada aqui é que, no caso dos verbos monoargumentais, o argumento presente ocupa obrigatoriamente a posição de sujeito. Se pensamos em dividir esses verbos em duas classes, temos que admitir que os sujeitos dessas classes devem ser interpretados de maneira diferente.

Observando as sentenças em (23), podemos comprovar que em (23a) o sujeito tem controle sobre a ação descrita pelo verbo, enquanto em (23b), não.

(23) a. A criança sorriu.

b. A criança cresceu.

É natural pensarmos que alguém pode sorrir a hora que quiser ou pode parar de sorrir por vontade própria. Já crescer não denota uma eventualidade que possa ser controlada. Nesse sentido, podemos dizer que o sujeito de sorrir é volitivo, já o de crescer, não. Por esse motivo, o particípio desses dois verbos se comporta de maneira diferente, no tocante à possibilidade de ocorrer como adjetivo:

(24) a. *A criança sorrida...

b. A criança crescida...

Isso nos permite delimitar as duas classes de verbos monoargumentais: os verbos que têm um sujeito volitivo (com características de um agente) e os que não têm sujeito volitivo.

A literatura lingüística prevê a existência de verbos inacusativos (ou ergativos, na terminologia de alguns autores). ${ }^{6}$ Em certas línguas, 
como o italiano, ${ }^{7}$ a distinção entre inacusativos e intransitivos é evidenciada por alguns fatos sintáticos (como a escolha de auxiliar, por exemplo). Já em português, a diferenciação não é sintaticamente explícita.

A idéia que está por trás dessa análise é a de que alguns verbos monoargumentais são marcados no léxico para atribuir um papel temático agentivo para o seu sujeito. Outros não têm capacidade de atribuir um papel temático a um sujeito. $\mathrm{O}$ argumento desses verbos, portanto, nasce como um argumento interno (como se fosse um complemento do verbo) e, pelo fato de esses verbos terem um único argumento, ele precisa necessariamente ocupar a posição de sujeito. Assim, alguns verbos monoargumentais, que vamos denominar aqui intransitivos, na sua origem, têm um argumento com todas as características de sujeito; outros, que vamos chamar de inacusativos, têm um argumento que, na sua origem, é um complemento interno (um objeto) e que, pela falta de outro argumento, precisa ocupar a posição de sujeito. Portanto, os verbos monoargumentais têm sujeitos com características semânticas bem distintas.

Assumindo a bipartição dos monoargumentais em intransitivos e inacusativos, ${ }^{8}$ podemos afirmar que apenas os inacusativos podem gerar um particípio capaz de atuar como adjetivo. Dessa forma, podemos correlacionar esse fenômeno com a possibilidade de os biargumentais poderem gerar sempre um particípio que atue como adjetivo: é o objeto direto dos biargumentais que será modificado pelo adjetivo participial. Como os inacusativos têm um sujeito "com cara de objeto”, esse sujeito também poderá ser modificado por um adjetivo participial.

Eliseu (1984), ao tratar o fenômeno da inacusatividade no português europeu, argumenta que os particípios dessa classe de verbos, quando monoargumentais, além de poderem atuar como predicativos e adjuntos do nome, podem, também, aparecer em construções absolutas, como exemplifica (25). 
(25) a. Crescidos os filhos, o casal pôde viajar com mais tranqüilidade.

b. Desaparecidos os documentos, o diretor tomou providências.

c. *Sorridas as crianças, tiramos uma fotografia.

d. *Corridos os atletas, o juiz deu o resultado.

Consideramos que construções absolutas constituem um fenômeno que tem interferência da natureza do verbo, ou seja, dos monoargumentais: somente os inacusativos ocorrem nesse contexto.? Parece não haver no português uma forma de constatação mais exata que delimite a classe dos inacusativos. O emprego do particípio acaba sendo a evidência mais ou menos precisa. Encontramos, na literatura, a tentativa de inserir outras evidências do comportamento dos inacusativos. Uma delas é a predisposição desses verbos de terem um sujeito posposto, isto é, a colocação do sujeito depois do verbo seria mais natural com os inacusativos, como aponta (26).

(26) a. Saíram as notas.

b. Chegaram as encomendas.

No entanto, o português permite essa posposição com outros verbos em determinados contextos. Ser mais ou menos natural não é um critério científico. Outra evidência seria a possibilidade de formar nominais com o sufixo -or. Esse sufixo forma nominais agentivos e, assim, seria um sinalizador para a classe dos intransitivos: descobridor é aquele que descobre. No entanto, não temos viajador, crescedor ou sorridor. Essas derivações, porém, sempre apresentam lacunas. Verbos intransitivos, como viajar ou sorrir, não formam viajador ou sorridor, porque a língua já dispõe de outras formas como viajante e sorridente. ${ }^{10}$ Este, portanto, também não constitui um indício seguro da intransitividade do verbo.

Esta pesquisa aponta para a necessidade de se investigar melhor o papel temático dos verbos. Explicamos que os particípios dos verbos monoargumentais podem ocorrer no contexto de adjunto adnominal e de predicativo se o verbo for inacusativo. Se olharmos para os trabalhos que procuram explicar a inacusatividade dos 
monoargumentais, veremos que um dos testes usados para o português é o fato de esses verbos poderem formar ou não particípios com valor de adjetivos. Estamos, portanto, diante de abordagens que são circulares. Uma saída seria direcionar a análise para outros fatores. Vimos que o objeto direto de um verbo biargumental é um candidato natural para ser modificado por um particípio adjetivo. Isso sinaliza para uma possível correspondência entre os complementos dos verbos biargumentais e os sujeitos dos inacusativos. É possível que o papel temático dos objetos seja, de alguma forma, correspondente ao papel temático do sujeito de um verbo inacusativo. Esse fato nos permite levantar algumas questões, como: seria o papel temático agente o único a ser excluído como argumento de um particípio adjetivo? Que papéis temáticos o argumento pode ter para ser modificado por um particípio adjetivo? Uma evidência da relevância dessas questões é a aceitação duvidosa do particípio de alguns verbos, tidos tradicionalmente como inacusativos, nessa posição. Exemplos desse tipo foram apresentados em (8)b e d e em (10)b e d, que repetimos aqui por conveniência.

(27) a. ?Os resultados saídos ontem não agradaram o pessoal.

b. ?A informação chegada no final da reunião animou o pessoal.

c. *Os resultados estão/são saídos.

d. *A informação está/é chegada.

Percebemos que os verbos de movimento e de direção resistem a esse emprego e, no entanto, isso não é suficiente para serem descartados da classe dos inacusativos. Isso reforçaria nossa posição de que é necessário investigar propriedades semânticas, possivelmente responsáveis pelas características sintáticas. Vimos, também, que noções como agente, tema, etc., são demasiadamente vagas. Por isso, optamos pela Teoria Generalizada dos Papéis Temáticos para a continuidade da análise. 


\section{A NATUREZA DOS PAPÉIS TEMÁTICOS}

A noção de papel temático está correlacionada com o esquema de seleção dos predicados, ou seja, cada predicado abre espaço para um número X de argumentos cuja presença (explícita ou implícita) na sentença é obrigatória. Se um verbo expressa uma atividade envolvendo dois argumentos, deve haver pelo menos dois constituintes na sentença que expressam esses argumentos. Se o falante sabe o significado de matar, por exemplo, também saberá quantos participantes estarão envolvidos e quantos argumentos o verbo exige.

Numa sentença como

(28) Carlos matou Pedro.

os dois argumentos, Carlos e Pedro, mantêm relações semânticas diferentes com o verbo. O argumento Carlos, na posição de argumento externo, refere-se à entidade que é Agente da atividade de matar. Pedro, o argumento interno, expressa o Paciente da ação. O papel temático revela o "papel" que cada argumento desempenha numa determinada eventualidade. Pode-se dizer, portanto, que matar toma dois argumentos, aos quais atribui papéis temáticos: o papel Agente para o argumento externo e o papel Paciente para o argumento interno. ${ }^{11}$

O predicado tem, assim, uma estrutura temática, e o componente da gramática que regula a atribuição de papéis temáticos é chamado de teoria temática na Gramática Gerativa. Essa teoria contém um componente conceptual, que se ocupa da caracterização semântica dos argumentos, e um componente formal, que tem a ver com as propriedades estruturais das representações sintáticas. Determinar critérios rigorosos formais para proceder à caracterização semântica das funções temáticas sempre foi um entrave para a teoria gramatical. Por exemplo, se se diz que Agente é aquele que é responsável pelo desencadeamento da ação, não se sabe se isso envolve ou não a intenção de desencadear. Observemos os exemplos em (29).

(29) a. O menino quebrou a vidraça.

b. O vento quebrou a vidraça. 
Em (29)a, não se sabe se houve ou não a intenção de desencadear a ação (o menino pode ter quebrado a vidraça sem a intenção de fazê-lo). Em (29)b, certamente não poderíamos atribuir intenção ao vento, agente desencadeador de quebrar a vidraça. Numa tentativa de contornar esses problemas com a identificação dos papéis temáticos, temos a Teoria Generalizada dos Papéis Temáticos que servirá de base para nossa análise.

\subsection{Teoria generalizada dos papéis temáticos}

A proposta intitulada Teoria Generalizada dos Papéis Temáticos se apóia na idéia de composicionalidade na atribuição de papéis temáticos proposta em Franchi (1994, 1997a e 1997b) e na prática de decompor esses papéis em acarretamentos lexicais, idéia defendida por Dowty (1989). Essa proposta ganha corpo na análise dos verbos psicológicos apresentada em Cançado (1995) e, mais recentemente, encontra-se sistematizada em Cançado (2003), trabalho que tomaremos como base para nossa exposição. Nessa proposta, assume-se que papéis temáticos são definidos como sendo o grupo de propriedades atribuídas a um determinado argumento a partir dos acarretamentos estabelecidos por toda a proposição em que esse argumento se encontra. "É exatamente o caráter mais flexível dos acarretamentos e a abordagem composicional dada às relações temáticas que permitem atribuir um estatuto teórico aos papéis temáticos, assumindo-os como parte de uma teoria gramatical" (CANÇADO, 2003, p. 95).

A vantagem da proposta é que ela reduz consideravelmente o número de noções comparando-se com a lista de papéis temáticos apresentada na literatura. Dessa forma, abandonam-se rótulos como agente, paciente e outros e procura-se formular propriedades semânticas acarretadas por um predicador a determinado argumento. Cançado assume que predicador não são apenas verbos, mas quaisquer itens lexicais (nome, verbo, adjetivo, advérbio e preposição).

Assim, em

(30) João quebrou o vaso com um martelo. 
o papel temático atribuído a João é o grupo de propriedades semânticas atribuídas a João, estabelecidas pelos acarretamentos decorrentes da proposição João quebrou o vaso com um martelo. Entendida a noção de acarretamento como uma relação entre duas proposições, A e B (em que se observa o seguinte princípio: se A é verdade, B é necessariamente verdade), deve-se testar cada acarretamento desta forma: se é verdade que João quebrou o vaso com um martelo, é necessariamente verdade que João:

- teve controle sobre o desencadeamento do processo;

- teve intenção de quebrar o vaso;

- e, conseqüentemente, é animado;

- usou um instrumento para tal ação, etc.

Esse grupo de propriedades semânticas apresentadas constitui o papel temático atribuído ao argumento João na proposição. Portanto, deve-se definir os acarretamentos que determinam certas propriedades semânticas que compõem o papel temático dos argumentos que são relevantes para a explicação de certas generalizações gramaticais, sem esquecer-se de que essas propriedades são dadas composicionalmente, ou seja, pelo conjunto de elementos envolvidos na predicação e não somente pelo verbo. Observemos os exemplos em (31).

(31) a. João recebeu uma bola dos amigos.

b. João recebeu uma bolada durante o jogo.

Embora o verbo seja o mesmo - receber -, os argumentos envolvidos denotam diferentes relações temáticas, que só podem ser evidenciadas pela noção de composicionalidade, isto é, pela relação entre o argumento e a expressão predicadora. Em (31)a, recebeu uma bola dos amigos acarreta que João tem controle sobre o processo, pois pode aceitar ou recusar a bola. Já em (31)b, João é somente um afetado no processo, sem nenhum sinal de volição. 
Reconhece-se, porém, que nem todo acarretamento tem relevância em uma análise gramatical, por isso Cançado (2003), empiricamente, define quais são as propriedades relevantes gramaticalmente, isto é, quais as propriedades semânticas que têm um papel relevante na ligação entre as estruturas sintática e semântica. A Teoria Generalizada dos Papéis Temáticos (TGPT) destaca quatro propriedades semânticas relevantes: ser desencadeador de um processo, ser afetado por um processo, estar em determinado estado e ter controle sobre um desencadeamento, processo ou estado, ou seja, desencadeador, afetado, estativo e controle. Com a ajuda de Wenceslau (2003), apresentamos essas propriedades a seguir.

\subsection{Propriedades semânticas definidoras de papéis temáticos}

\section{a) Desencadeador (D)}

Podemos atribuir a propriedade desencadeador a um argumento, quando ele tem algum papel no desenrolar do processo. É o que se pode observar do argumento João, na sentença a seguir.

O João ajudava as vítimas da enchente.

Se é verdade que João ajudava as vitimas da enchente, é necessariamente verdade que João desencadeou (ou deu início a) a ação de "ajudar".

\section{b) Afetado (A)}

Ao argumento que acarreta a mudança de um estado A para um estado $B$ pode-se atribuir a propriedade afetado. Na sentença (32), o argumento as vítimas da enchente passa de um estado "sem ajuda" para um estado "serem ajudadas", isto é, o argumento é afetado pelo processo. Inclui-se também como afetado todo argumento do qual se acarreta mudança de um local A para um local B-ser deslocado-ou mudança de posse entre $A$ e $B$. 


\section{c) Estativo (E)}

A propriedade semântica estativo é identificada em argumento do qual se acarreta estar em determinado estado, ou seja, a propriedade não se altera durante um intervalo de tempo. Diz-se que o argumento tem a propriedade estativo, quando ele apresenta propriedades tais como ser a fonte ou ser o alvo de um deslocamento e também ser o lugar - o locativo propriamente dito.

\section{d) Controle (C)}

A propriedade controle é identificada em argumento do qual se acarreta poder iniciar ou interromper um processo. Por exemplo, temos controle em:

(33) a. João abandonou os estudos.

b. O governo doou verbas aos desabrigados.

Nessas sentenças, tanto João como o governo acarretam a propriedade desencadeador, por iniciarem os processos descritos, e também controle, pois podem interromper o processo em qualquer momento. Para detectar o controle, Cançado (2003) propõe o seguinte teste para mostrar que os argumentos têm controle sobre tais processos, pois podem impedi-los ou interrompê-los.

(34) a. João não vai mais abandonar os estudos.

b. O governo não vai mais doar dinheiro aos desabrigados.

Diferentemente das outras propriedades, o controle não ocorre isoladamente: estará sempre associado a uma outra propriedade e sempre relacionado à animicidade do argumento. Desse modo, podemos ter um argumento que acarreta a propriedade desencadeador com controle ou desencadeador sem controle. Essa característica se aplica às outras duas propriedades.

Cançado expõe, a partir dessas noções, os pressupostos do Princípio de Hierarquia Temática, a saber: 
$1^{\circ}$ ) o Princípio se vale de propriedades semânticas - desencadeador, afetado, estativo e controle - e não mais dos tradicionalmente conhecidos papéis temáticos - agente, paciente, entre outros;

$2^{\circ}$ o Princípio estabelece a correlação entre as propriedades semânticas e as posições argumentais do predicado - os argumentos externo e interno.

$3^{\circ}$ ) o Princípio se vale de toda a proposição para a atribuição das propriedades que compõem o papel temático.

A partir das noções e dos princípios, Cançado estabelece a Hierarquia Temática, ou seja, estabelece a correlação entre as propriedades dos argumentos e as posições sintáticas de argumento externo e interno. Como nosso objetivo aqui é observar as propriedades do único argumento dos verbos inacusativos, não vamos entrar nos detalhes da hierarquia.

\subsection{Propriedades semânticas dos argumentos de verbos monoargumentais}

Vimos que a diferença entre verbos intransitivos e inacusativos é que, enquanto aqueles possuem um argumento que é gerado como argumento externo (portanto o verbo atribui papel temático ao seu sujeito), estes têm um argumento gerado como argumento interno (i.e., o verbo não atribui papel temático a um sujeito), que, por ser único, precisa ocupar a posição de sujeito. Concluímos, intuitivamente, que o sujeito dos intransitivos apresenta características de volição, ao contrário do sujeito dos inacusativos. Nossa hipótese é que as propriedades semânticas desses argumentos são responsáveis por permitir ou bloquear o uso do particípio como modificador do nome. Vamos, a partir de agora, analisar esses argumentos segundo critérios da TGPT. Em outras palavras, vamos observar as propriedades que certos argumentos possuem em relação aos seus predicadores. 


\subsubsection{Os verbos intransitivos}

Observa-se que os argumentos dos verbos intransitivos têm algum papel no desenrolar do processo, podendo-se associar a eles a propriedade Desencadeador. De algum modo, esses argumentos são responsáveis pelo desenrolar do processo. Observemos os exemplos em (35).

(35) a. Os atletas correram $4 \mathrm{Km}$.

b. A criança sorri.

c. O chefe telefonou.

Em (35)a, os atletas desencadeiam a ação de correr. Podemos dizer também que eles têm controle sobre o processo, pois podem interrompê-lo, se quiserem. Por esse motivo, podemos também associar a eles a propriedade Controle. Isso pode igualmente ser observado em relação aos demais argumentos em (35)b e (35)c. Os testes seguintes comprovam essa questão.

(36) a. Os atletas não vão mais correr hoje. Já decidiram isso.

b. A criança não quer mais sorrir, pois não lhe deram o que pedia.

c. O chefe não vai mais telefonar. Recusou-se a isso.

Os intransitivos, cujos argumentos possuem as propriedades DC, não permitem que seu particípio modifique um nome dentro do sintagma nominal, como se pode ver nos exemplos em (37).

(37) a. *Os atletas corridos ontem ...

b. *A criança sorrida ...

c. *O chefe telefonado ...

Há alguns intransitivos, no entanto, que não apresentam a propriedade $\mathbf{C}$. Podemos afirmar que, nesses casos, os predicadores atribuem a propriedade $\mathbf{D}$, mas sem controle, como se observa em (38).

(38) a. O avião voa por entre as nuvens.

b. A porta rangeu estrondosamente. 
Também nesses casos, não temos a possibilidade de usar o particípio como adjetivo adjunto ao nome, o que mostra que a propriedade $\mathbf{C}$ não é a única responsável por essa restrição.

(39) a. *O avião voado ...

b. *A porta rangida ...

Se a nossa análise estiver correta, parece ser a propriedade $\mathbf{D}$ a responsável pela restrição do particípio. Inserem-se, aí, predicadores como dormir, espirrar, latir, miar, fugir. ${ }^{12}$

\subsubsection{Os verbos inacusativos canônicos}

Estamos chamando de canônicos os verbos mais representativos do grupo em relação ao comportamento do particípio. O argumento de um verbo inacusativo, por ser gerado como argumento interno, não é responsável pelo desencadeamento de um processo ou ação, como podemos observar em (40).

(40) a. As folhas caem no outono.

b. A fábrica faliu.

c. O barraco desabou morro abaixo.

d. As crianças crescem depressa.

Pode-se dizer que esses argumentos "sofrem a ação" e mudam de estado. Logo, possuem a propriedade Afetado. Falta verificar se também possuem a propriedade $\mathbf{C}$, já que a teoria prevê a possibilidade de combinação do controle com qualquer outra propriedade.

(41) a. *As folhas vão parar de cair. Elas já decidiram.

b. *A fábrica não vai mais falir, porque ela resolveu se reerguer.

c. *O barraco não vai mais desabar.

d. *As crianças decidiram não crescer mais.

Os exemplos em (41) demonstram que não há controle sobre os processos descritos. Os argumentos têm características passivas, 
característica de argumento interno, sem a possibilidade de interromper a atividade em desenvolvimento. Os particípios derivados desses verbos permitem o seu uso na posição de adjunto do nome, como se pode conferir nos exemplos em (42).

(42) a. As folhas caídas são levadas pelo vento.

b. A fábrica falida terá ajuda da comunidade.

c. O barraco desabado atingiu outras casas.

d. As crianças crescidas dão mais trabalho.

\subsubsection{Outros verbos inacusativos}

De modo geral, a literatura sobre verbos inacusativos cita o verbo chegar como um exemplo indiscutível dessa classe. No entanto, nossa pesquisa mostrou que esse verbo e todos os que denotam movimento e direção têm um comportamento não canônico no que se refere ao uso do particípio como modificador do nome. Também não é tranqüila a atribuição de uma ou outra propriedade semântica aos argumentos desses verbos. Se o argumento é animado, parece-nos plausivel dizer que ele desencadeia o processo: alguém que chega ou que sai pode dar início ao processo por vontade própria. Contudo, não fica claro se podemos atribuir controle ao processo. Vejamos:

(43) a. João chegou tarde na festa.

b. Os alunos saíram da sala antes do término da aula.

Achamos que não seria apropriado falar que João e os alunos foram de algum modo afetados. Eles parecem ter aí algum papel no desenrolar do processo, portanto, com propriedade D. Mas não se pode afirmar que há controle, como se pode ver a seguir:

(44) a. *João parou de chegar na festa.

b. *Os alunos pararam de sair antes do término da aula.

Vale observar que as sentenças em (44) não são estranhas se pensarmos que os eventos se dão iterativamente, ou seja, diante de 
várias eventualidades de chegar e de sair, pode-se dizer que alguém parou de sair ou de chegar. Mas as ocorrências são estranhas se tivermos em mente uma única atividade de chegar ou de sair. Tendo isso em vista, temos argumentos com propriedade $\mathbf{D}$ sem controle, igual aos argumentos dos intransitivos. A restrição para o uso do particípio, nesses casos, confirma essa observação.

(45) a. *O menino chegado ...

b. *Os alunos saídos da sala ...

No entanto, se tivermos aí um argumento inanimado, não podemos mais falar em propriedade $\mathbf{D}$ e, muito menos, em propriedade C. Por denotar mudança de um lugar para outro, é possível atribuir aos argumentos a propriedade A. Nesses casos, o uso do particípio é bem mais aceitável.

(46) a. As cartas chegaram com atraso.

b. As cartas chegadas com atraso ...

(47) a. As notas saíram na semana passada.

b. ?As notas saídas na semana passada ...

Com isso, pudemos detalhar um pouco mais a restrição que opera sobre os particípios quando usados como adjetivos e contribuir um pouco, também, para a discussão do fenômeno da inacusatividade no português brasileiro.

\section{CONCLUSÕES}

Este trabalho serviu para uma descrição mais detalhada da ocorrência dos particípios como adjetivos na posição de adjunto do nome e de predicativo. Mostramos que o particípio, nesses casos, se comporta como um adjetivo e que o argumento que ele é capaz de modificar precisa ter, necessariamente, características de argumento interno. Incluímos, nesse rol, o objeto direto dos verbos biargumentais e o sujeito dos verbos inacusativos. Procurando entender melhor as restrições que operam sobre o emprego do 
adjetivo participial, lançamos mão da TGPT e mostramos que é possível explicar essas restrições observando as propriedades semânticas apresentadas pelos argumentos modificados pelos adjetivos participiais.

\section{NOTAS}

* Agradecemos ao CNPq o apoio financeiro.

${ }^{1}$ A Gramática Gerativa enuncia essa bipartição da sentença por meio do Princípio de Projeção Estendida (EPP), que prevê que toda sentença deve ter sujeito.

${ }^{2}$ Não estamos levando em conta, aqui, a defectividade de alguns verbos em relação à posição de sujeito: há verbos que não têm sujeito, pelo menos, de forma explícita.

${ }^{3}$ Selecionamos, aqui, os ambientes mais relevantes para este trabalho. O particípio pode, ainda, ocorrer em outros, como em construções absolutas participiais (Terminada a aula, todos saíram da sala) e em construções com verbo leve (Ele deu uma dormida durante a conferência).

${ }^{4}$ A flexão de gênero e número não deve ser tomada como evidência indiscutível da natureza nominal do particípio. Em francês, essa flexão ocorre também no particípio formador de tempo composto e nem por isso se levantam dúvidas de sua natureza verbal nessas construções.

${ }^{5}$ Apesar de sabermos da imprecisão que envolve a noção de agente, vamos usála por enquanto. Mais adiante, substituiremos essa nomenclatura.

${ }^{6}$ A esse respeito, ver Eliseu (1984).

${ }^{7}$ A esse respeito, ver Burzio (1986).

${ }^{8}$ Para maiores detalhes, ver Nascimento (2002).

${ }^{9}$ A esse respeito, ver Kochanowski (2003).

${ }^{10}$ Essa é uma tendência que também mereceria ser investigada, pois a terminação -nte sinaliza um particípio presente e parece ser mais afeita aos verbos intransitivos (viajante, sorridente). Mas também aí há muitas lacunas (*telefonante, por exemplo) e evidências contrárias (como crescente).

${ }^{11}$ Essa é uma apresentação bastante superficial de papel temático. Para maior aprofundamento, ver Fillmore (1968) e Jackendoff (1972).

${ }^{12}$ Essa relação de predicadores serve apenas como parâmetro. Não podemos esquecer que a TGPT vai sempre se basear no princípio da composicionalidade. Não é o item lexical que atribui as propriedades semânticas a seus argumentos. Isso depende do emprego de cada item com outros elementos do predicado. 


\section{REFERÊNCIAS BIBLIOGRÁFICAS}

BURZIO, L. Italian syntax: a governmente and binding approach. Dordrecht: D. Reisel Publishing Company, 1986.

CANÇADO, M. Verbos psicológicos: A relevância dos papéis temáticos vistos sob a ótica de uma Semântica Representacional. 1995. Tese (Doutorado) - Unicamp, Campinas.

. Um estatuto teórico para os papéis temáticos. In: MÜLLER, A. et al. Semântica Formal. São Paulo: Contexto, 2003.

DOWTY, D. On the semantic content of the notion of thematic role. In: CHIERCHIA; PARTEE; TURNER (Ed.). Properties, types and meaning. Studies in Linguistic and Philosophy, 2: Semantic Issues. Dordrecht: Kluwer, p. 69-129, 1989.

ELISEU, M. Verbos ergativos. 1984. Dissertação (Mestrado) - Universidade de Lisboa, Lisboa.

FILLMORE, C. The case for case. In: BACH, E.; HARMS, R. (Ed.). Universals in Linguistic Theory. New York: Holt, Rinnehart and Winston, 1968.

FRANCHI, C. Anotações sobre a Teoria Generalizada dos Papéis Temáticos. Unicamp, 1994. (Manuscrito) . Predicação. Unicamp/USP, 1997a. (Manuscrito) . Teoria da Adjunção. Unicamp/USP, 1997b. (Manuscrito)

JACKENDOFF, R. Semantic interpretation un Generative Grammar. Cambridge (MA): MIT Press, 1972.

KOCHANOWSKI, S. Construções absolutas participiais do PB. 2003. Dissertação (Mestrado) - Universidade Federal do Paraná, Curitiba.

NASCIMENTO, S. H. L. do. Inacusatividade no português do Brasil. 2002. Tese (Doutorado) - Universidade Federal de Santa Catarina, Florianópolis.

PIMENTA-BUENO, M. N. S. As formas [v+do] em português: um estatuto de classes de palavras. D.E.L.T.A, São Paulo, v. 2, p. 207-229, 1986.

WENCESLAU, F. de Lima. Verbos Beneficiários: um estudo na interface semântica e sintaxe. 2003. Dissertação (Mestrado) - Universidade Federal de Minas Gerais, Belo Horizonte. 